\title{
Sex differences in adult craniofacial parameters
}

\author{
Suat Avci ${ }^{1} \cdot$ Tarkan $_{\text {Ergun }^{2}} \cdot$ Erdinc Aydin ${ }^{1} \cdot$ Leyla Kansu $^{1}$
}

Received: 16 July 2014/Accepted: 25 April 2015/Published online: 3 May 2015

(c) The Author(s) 2015. This article is published with open access at Springerlink.com

\begin{abstract}
Purpose To compare normal male and female craniofacial parameters in adults and evaluate associations of sex and intercochlear distance with other craniofacial parameters.

Methods In 60 normal adults (30 men and 30 women) who had no otitis media, craniofacial parameters were measured retrospectively on two-dimensional reformatted computed tomography scans.

Results Compared with women, men had significantly greater mean osseous auditory tube length, cartilaginous auditory tube length, mastoid length, intercochlear distance, sella to posterior nasal spine distance, sella to basion distance, and nasopharynx sagittal area. The intercochlear distance was significantly correlated with mastoid depth, midpoint of the pharyngeal opening distance, sella to nasion distance, and nasopharynx sagittal area and inversely with angle of the auditory tube. Most men and women had Körner septum present, and mean thickness of Körner septum was significantly greater in men than women.

Conclusions Some craniofacial parameters, especially vertical parameters, differ with sex. These differences begin in childhood and continue in adulthood. Sex must be considered when planning a craniofacial morphologic study, and results of a craniofacial morphologic study
\end{abstract}

Suat Avci

suat_avci2002@yahoo.com

1 Department of Otolaryngology-Head and Neck Surgery, Baskent University, Saray Mah. Yunusemre Cad. No. 1, Alanya, 07400 Antalya, Turkey

2 Department of Radiology, Baskent University, Ankara, Turkey should be evaluated with caution when there is no sex matching of the patient and control groups.

Keywords Anatomy $\cdot$ Skeleton $\cdot$ Head $\cdot$ Chronic otitis media $\cdot$ Computed tomography

\section{Introduction}

In infants and children, synchronized growth of the craniofacial skeleton is associated with development of the auditory tube system. Abnormal growth or synchronization during development may adversely affect the anatomy and function of the auditory tube system and predispose to otitis media [3, 10]. Most cases of otitis media with effusion resolve spontaneously by age of 10 years, but chronic otitis media is a common problem worldwide [12]. It is unknown how or why otitis media may become chronic, but genetic and environmental factors may contribute to disease progression [19].

Patients who have chronic otitis media may differ from control groups in nasopharyngeal size [12], facial morphology $[4,5,10,13]$, length and angle of cranial base components $[5,10]$, the bony portion of the auditory tube $[12,22]$, projections of the auditory tube and associated musculature onto the parasagittal plane [10], mastoid size and degree of pneumatization, jugular bulbus height, and presence and size of Körner septum. These relations have been evaluated in cadaver specimens with lateral cephalometric radiographs, computed tomography (CT), and magnetic resonance imaging. However, it is difficult to synthesize these results because of differences in study design and technique [3]. Cephalometry may not image the auditory tube system directly, and the proposed effects of craniofacial development on the auditory tube system are 
inferred [3]. In addition, studies vary in patient age, and craniofacial patterns and auditory tube-middle ear system morphology may vary with age [3].

In a previous study, two-dimensional reformatted CT images were used for cephalometric assessment, and when sex, age and race are considered there were no differences in most craniofacial parameters between adults who had chronic otitis media and healthy subjects, except small mastoid size (mastoid depth and length) correlated with chronic otitis media [1].

However, some previous craniofacial morphologic studies did not evaluate the effect of sex on craniofacial parameters. Compared with women, men have more massive muscles and body organs, their lungs are larger, and they need a larger airway beginning with the nose and nasopharynx; these differences in size and configuration of the nose may cause collateral differences in other topographic structures [6]. In addition, morphologic measurements in normal subjects may be useful in the study of patients who have chronic otitis media.

The purpose of the present study was to evaluate and compare craniofacial parameters in normal male and female Turkish adults using two-dimensional reformatted CT scanning, and to evaluate the effect of sex and breadth of the cranial base, measured by the intercochlear distance (IcD), in craniofacial morphologic studies. These data may provide additional information to verify more realistically the association between otitis media and craniofacial morphology.

\section{Materials and methods}

\section{Subjects}

This retrospective study was performed with two-dimensional reformatted CT scans from 60 adults who had healthy ears. There were 30 men (age: mean 37 years; range 19-74 years) and 30 women (age: mean 39 years; range 25-72 years). The subjects were selected from patients who had been referred for a CT scan for evaluation of a space-occupying lesion, trauma, or malformation of the temporal bone. Patients who had CT abnormalities of the internal auditory canal or temporal bone were excluded from the study. Criteria for a normal temporal CT scan included absence of bony destruction or sclerosis, absence of fluid or mass in all temporal bone air spaces, and presence of normal air cells with a sharp, well-defined mucoperiosteal margin and no septal thickening.

\section{Imaging}

The CT scans (Siemens Hi-Speed CT scanner, Siemens, Erlangen, Germany) were performed with scan parameters
$120 \mathrm{kV}, 300 \mathrm{~mA}, 1-\mathrm{mm}$ slice thickness, zero interslice gap, and $512 \times 512$ matrix. The axial scans were parallel to the orbitomeatal line. The image data were transferred to a workstation (GE Advantage, Windows version 4.2, GE Medical Systems, Wilmington, MA, USA). An experienced radiologist and otolaryngologist worked together to reformat each CT scan for accurate landmark identification.

Axial images were transformed to oblique reformatted images to measure auditory tube length. The pharyngeal openings of the auditory tube were determined on the axial plane, and a cursor was placed in the middle of a line joining the openings (Fig. 1).

\section{Auditory tube parameters}

The axial CT image was rotated coronally, and oblique coronal reformatted CT images were obtained. To solve the asymmetry problem arising from patient position, the angle of the reformatted image was adjusted until basal turns of both cochleae became visible. The images were standardized for all patients; reference points and lines were defined, and multiple measurements (linear, angular, and area measurements) were made from each CT scan (Table 1; Figs. 1, 2, 3, 4, 5, 6, 7, 8). Reformatted images were recorded on a workstation program, and measurements were done electronically. Measurements were performed twice at different sessions for each patient, and arithmetic means were calculated to minimize random erroneous measurements.

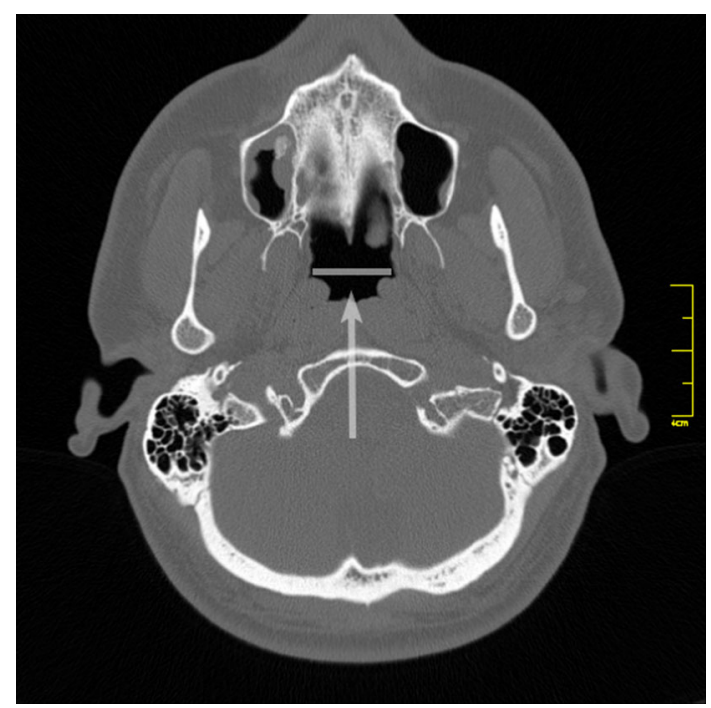

Fig. 1 Craniofacial computed tomography scan. Pharyngeal openings of the auditory tube were determined on the axial plane. The cursor (arrow) was placed in the middle of a line joining the openings of the auditory tube 
Table 1 Definitions of reference points, reference lines, and parameters from craniofacial computed tomography scans

\begin{tabular}{|c|c|}
\hline \multicolumn{2}{|l|}{ Category } \\
\hline Abbreviation & Item \\
\hline \multicolumn{2}{|c|}{ Reference points } \\
\hline ans & Anterior nasal spine \\
\hline pns & Posterior nasal spine \\
\hline ba & Basion \\
\hline hs & Henle suprameatal spine \\
\hline $\mathrm{n}$ & Nasion \\
\hline $\mathrm{s}$ & Sella \\
\hline ss & Sigmoid sinus \\
\hline Mpto & Midpoint of tympanic opening of auditory tube \\
\hline Ist & Isthmus \\
\hline Мppo & Midpoint of pharyngeal opening of auditory tube \\
\hline \multicolumn{2}{|c|}{ Reference lines } \\
\hline NSL & Nasion-sella line \\
\hline SbaL & Sella-basion line (posterior cranial base line) \\
\hline IcL & Intercochlear line \\
\hline OATL & Osseous auditory tube line \\
\hline \multicolumn{2}{|c|}{ Linear parameters } \\
\hline OAT & Osseous auditory tube length \\
\hline CAT & Cartilaginous auditory tube length \\
\hline IcD & Intercochlear distance \\
\hline s-n & Anterior cranial base-ACB-length \\
\hline s-pns & Posterior upper face height (PUFH) \\
\hline s-ba & Posterior cranial base (PCB) length \\
\hline hs-ss & Mastoid depth \\
\hline $\mathrm{ml}$ & Mastoid length \\
\hline ss-jb & Height of the jugular bulb \\
\hline $\mathrm{KS}$ & Körner (petrosquamosal) septum \\
\hline Mppod & \\
\hline \multicolumn{2}{|c|}{ Angular parameters } \\
\hline AAT & Angle of the auditory tube \\
\hline CBA & Cranial base angle \\
\hline A & Angle ba.s.pns \\
\hline
\end{tabular}

Area parameters

$\begin{array}{ll}\text { Npax } & \text { Nasopharynx axial area } \\ \text { Npsag } & \text { Nasopharynx sagittal area }\end{array}$

Definition

Midpoint of anterior edge of nasal spine

Midpoint of posterior edge of hard palate (staphylion)

Most posteroinferior point of spheno-occipital bone on anterior margin of foramen magnum

Henle suprameatal spine

Most anterior point of frontonasal suture

Center of sella turcica

Sigmoid sinus

Midpoint of tympanic opening of auditory tube

Most distal visible end of the bony auditory tube

Point nearest pharynx where a loop-shaped auditory tube lumen appears

Line through nasion and sella

Line through sella and basion

Line through cochleae

Line through "Mpto" and isthmus

Distance from "Mpto" to isthmus

Distance from isthmus to the "Mppo"

Distance between most lateral points of basal turns of cochleae

Distance from sella to nasion

Distance from sella to posterior nasal spine

Distance from sella to basion

Shortest distance between base of hs (lateral border) and sigmoid sinus

Shortest distance between mastoid tip and tegmen tympani

Distance between level of jugular bulb dome and line passing through confluence of the sigmoid sinus with jugular bulb

Thickness of septum measured at thickest point on coronal image

Distance between the midpoints of the pharyngeal openings

Angle between IcL and OATL

Angle between NSL and SbaL (ba.s.n)

Angle (measured at sella) between SbaL and line through sella and posterior nasal spine

Area between midpoints of pharyngeal openings of auditory tube (Mppo) and posterior border of pharyngeal soft tissue

Area between posterior border of vomer, inferior border of sphenoid sinus, anterior border of clivus, and basion to posterior nasal spine line
The distance between midpoint of the tympanic openings of the auditory tube and the most distal visible end of the bony auditory tube (isthmus) was defined as the osseous auditory tube length (Table 1; Fig. 2). The distance between the isthmus and the midpoint of the pharyngeal openings of the auditory tube was defined as the cartilaginous auditory tube length (Table 1; Fig. 2). For measurement of the intercochlear distance, which was the breadth of the cranial base, the cursor was placed on the anterior nasal spine; the image was rotated coronally until both basal turns came into sight; and the intercochlear distance was measured as the distance between the most lateral points of the basal turns of the cochleae (Table 1; Fig. 3). 



Fig. 2 a Oblique coronal schematic illustration showing the auditory tube and related structures. b Reformatted oblique coronal computed tomography image showing reference points and lines. CAT cartilaginous auditory tube length, $c$ cochlea, $I A C$ internal acoustic canal, IcL intercochlear line, Ist isthmus, Mppo midpoint of the pharyngeal opening of the auditory tube, Mpto midpoint of the tympanic opening of the auditory tube, OAT osseous auditory tube length, $p$ pharynx

Mastoid depth was defined as the distance between Henle suprameatal spine and the sigmoid sinus (Table 1; Fig. 4). The cursor was placed in the middle of the line joining right and left Henle spines to obtain an oblique axial image in which both the longest lengths of both Henle spines were observed. The shortest distance between the base of Henle spine and the anterior edge of the sigmoid sinus was measured as mastoid depth (Fig. 4). To measure the mastoid length, the angle of the reformatted coronal image was adjusted until the most inferior point of both mastoid tips came into view; images were standardized for

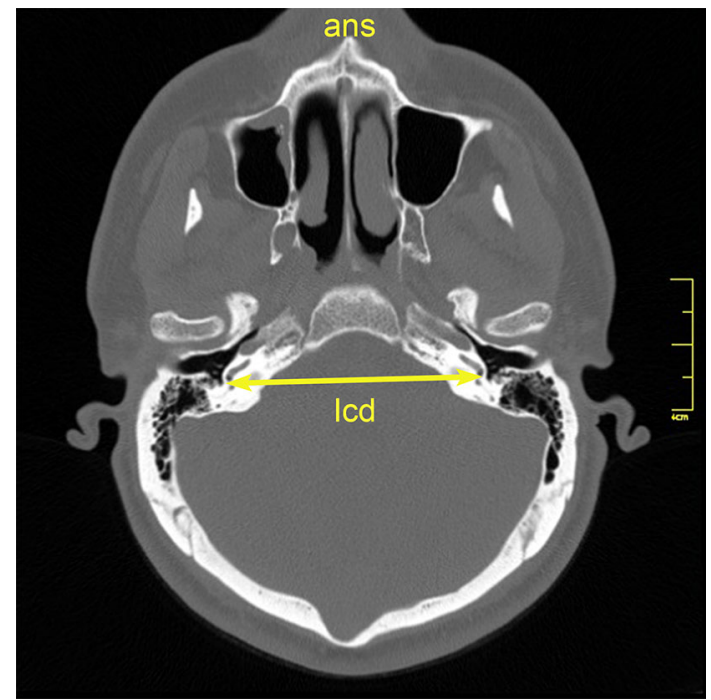

Fig. 3 Reformatted computed tomography image showing intercochlear distance $(I c D)$ and anterior nasal spine (ans)

(a)
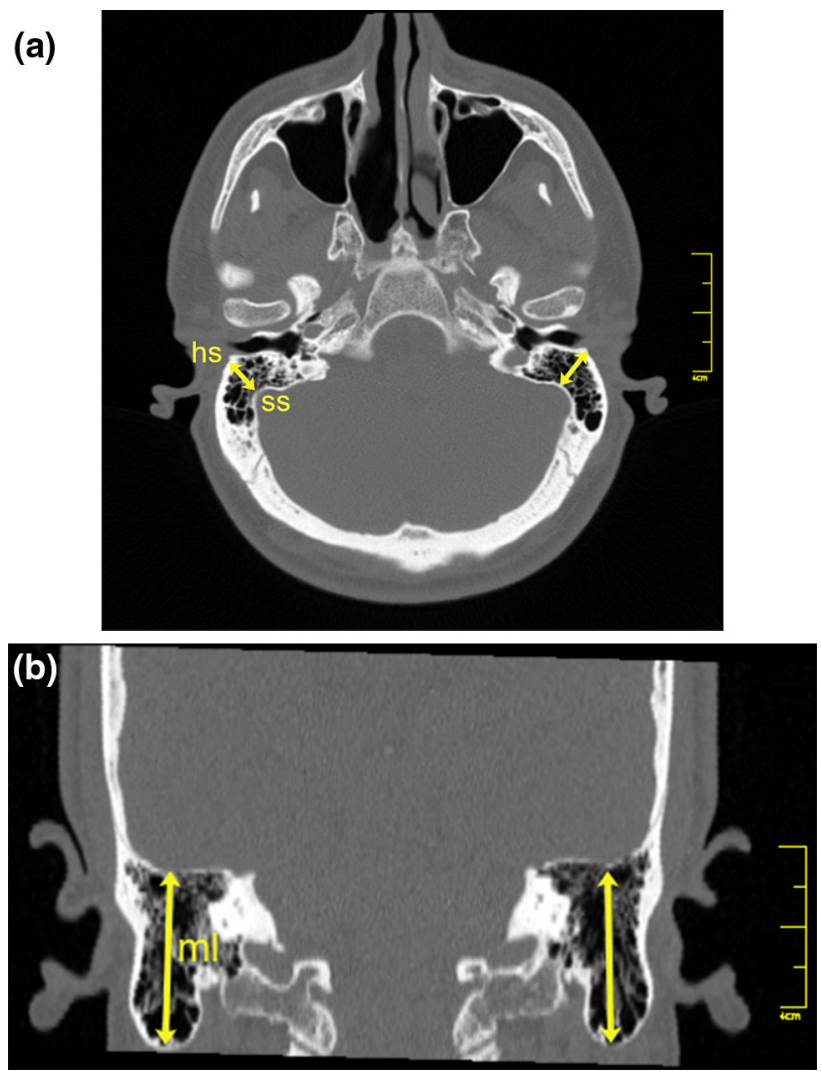

Fig. 4 Reformatted computed tomography images. a Oblique axial image showing Henle suprameatal spine $(h s)$ to sigmoid sinus (ss) distance (mastoid depth). b Coronal image showing mastoid length $(\mathrm{ml})$ which was the shortest distance between the mastoid tip and tegmen tympani

all patients, and the mastoid length was measured as the shortest distance between the mastoid tip and the tegmen tympani (Table 1; Fig. 4). 

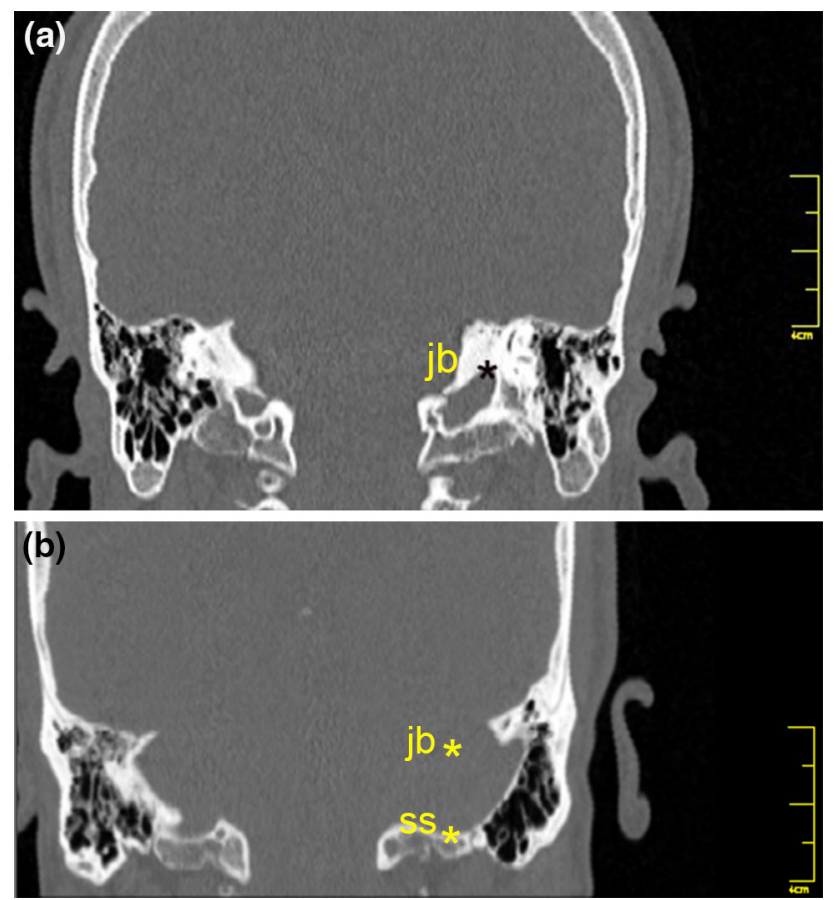

Fig. 5 Reformatted coronal computed tomography images. a The cursor is on the highest point of the jugular bulb. b The deepest point of the sigmoid sinus ( $s s$ ) is noted, and the height of the jugular bulb $(s s-j b)$ is the distance between level of the jugular bulb dome and a line passing through confluence of the sigmoid sinus (ss) with jugular bulb

Height of the jugular bulb was the distance between the level of the jugular bulb dome and the line passing through the confluence of the sigmoid sinus. The cursor was placed on the highest point of the jugular bulb on the coronal image (Fig. 5); sections were followed posteriorly until the deepest point of the sigmoid sinus came into view, and the distance between the cursor and the sigmoid sinus was measured (Table 1; Fig. 5). The presence and thickness of Körner (petrosquamosal) septum were assessed on both axial and coronal images (Table 1; Fig. 6). Cephalometric measurements were obtained on the reformatted midsagittal image (Fig. 7). Nasopharynx axial area and distance between midpoints of pharyngeal openings were measured from the oblique axial images, and the nasopharynx sagittal area was measured on the midsagittal images (Table 1; Fig. 8).

\section{Statistical analyses}

Data analysis was performed with statistical software (IBM SPSS for Windows, Version 21.0, IBM Corp, Armonk, NY, USA). Continuous variables were reported as mean \pm standard deviation. Normality of the continuous variables was evaluated with Shapiro-Wilk test. Differences in continuous variables between two groups were
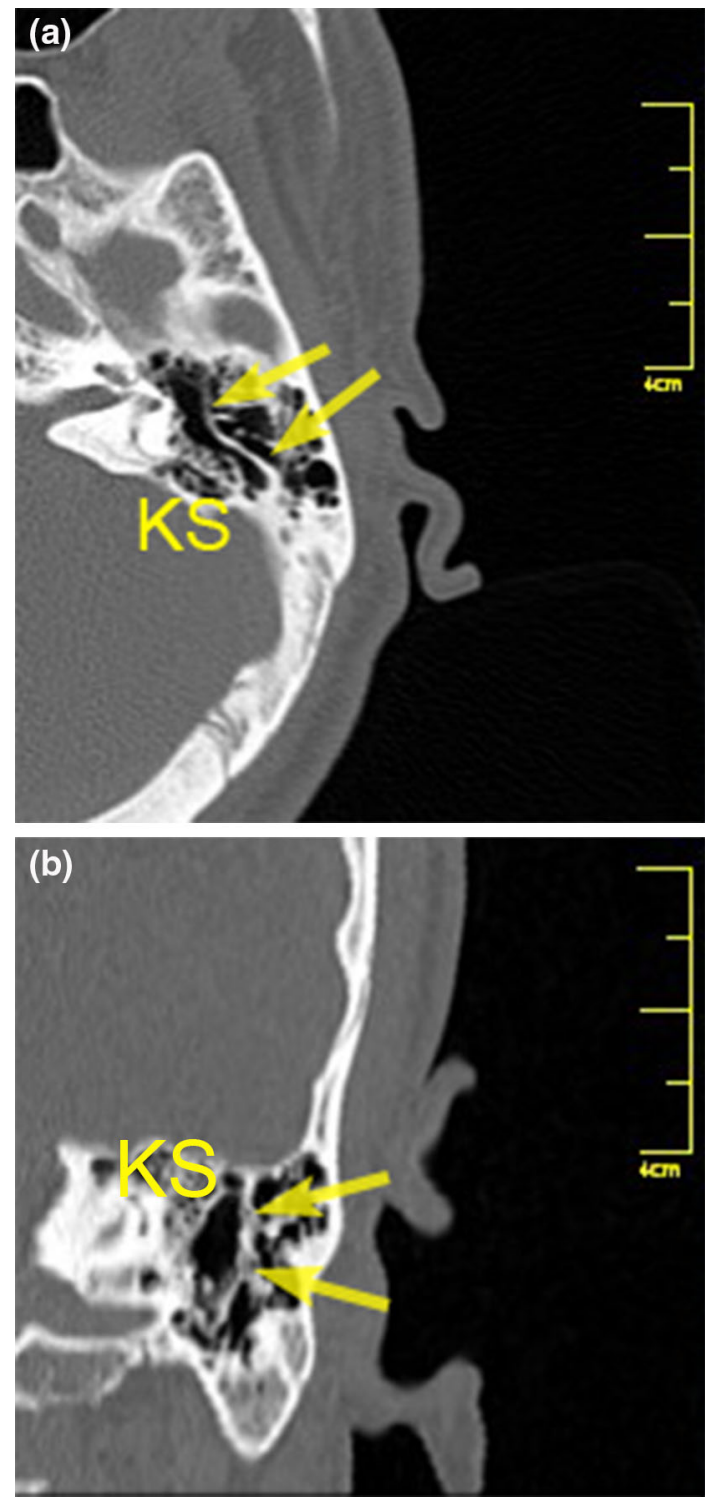

Fig. 6 Reformatted computed tomography images. a Oblique axial image. b Coronal image. The Körner (petrosquamosal) septum $(K S)$ is noted

evaluated with $t$ test for independent samples. Comparison of mastoid size and jugular bulb height for ears that had presence or absence of Körner septum was performed with Mann-Whitney test. Relation between continuous variables was evaluated with Pearson product moment correlation. Statistical significance was defined by $P \leq .05$.

\section{Results}

Compared with women, men had significantly greater mean osseous auditory tube length, cartilaginous auditory tube length, mastoid length, intercochlear distance, sella to posterior nasal spine distance, sella to basion distance, and 



Fig. 7 a Schematic representation of the midsagittal structures and landmarks. b Reformatted midsagittal computed tomography image. $A$ angle (measured at center of sella turcica) between sella-basion line and line through center of sella turcica and posterior nasal spine. ANS anterior nasal spine, $b a$ basion, $h p$ hard palate, $P N S$ posterior nasal spine, $n$ nasion, $s$ center of sella turcica

nasopharynx sagittal area (Table 2). There were no differences in the other parameters between men and women (Table 2).

The intercochlear distance was significantly correlated with mastoid depth, midpoint of the pharyngeal opening distance, sella to nasion distance, and nasopharynx sagittal area and inversely with angle of the auditory tube (Table 3). Most men and women had Körner septum present, and mean thickness of Körner septum was significantly greater in men than women (Table 4). Mean mastoid depth, mastoid length, and jugular bulb height were similar in patients who had Körner septum present or absent (Table 4).

\section{Discussion}

In the present study, craniofacial measurements in a homogenous population of Turkish people who had no otitis media showed that several mean parameters were greater in men than women (Table 2). In addition, the intercochlear distance (breadth of cranial base) was significantly correlated with several craniofacial parameters (Table 3). (a)
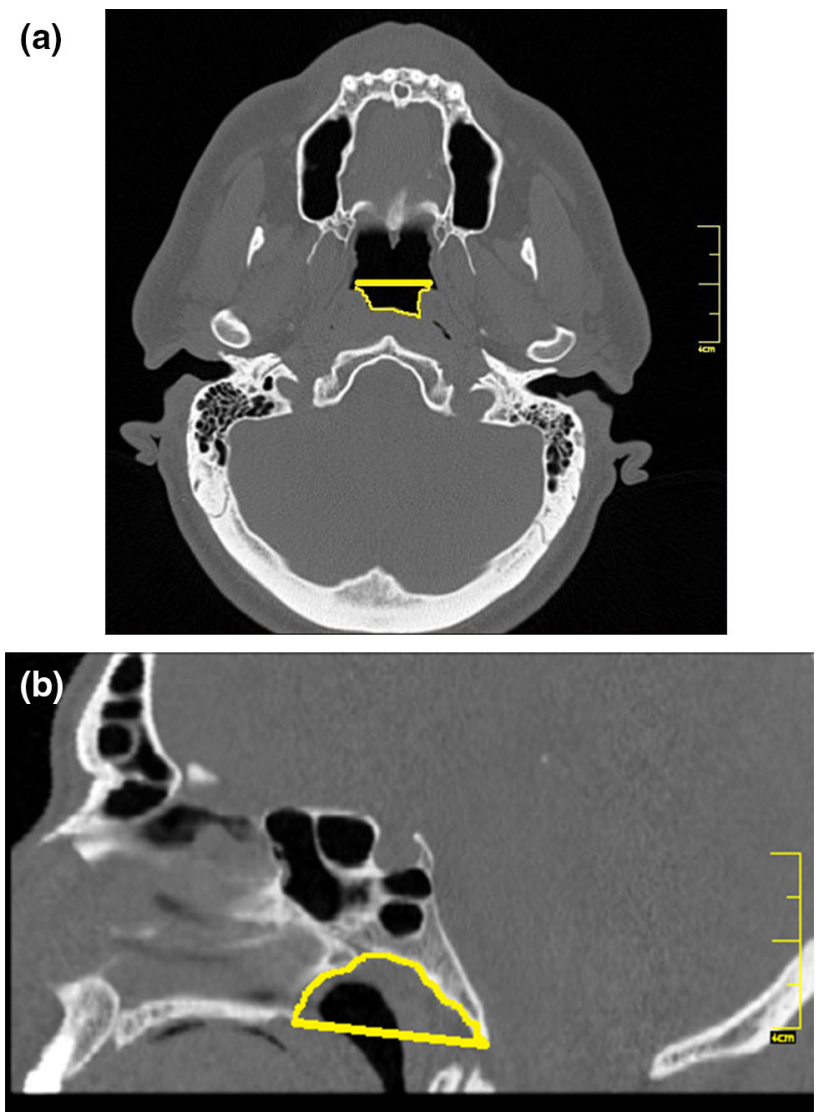

Fig. 8 Reformatted computed tomography images. a Oblique axial image showing nasopharynx axial area (Npax) and the distance between the midpoints of the pharyngeal openings (Mppod). b Midsagittal image showing nasopharynx sagittal area (Npsag)

Reformatted two-dimensional CT scanning may enable measurement of midsagittal parameters and bilateral craniofacial antimeric parameters in living subjects. However, CT scanning requires more radiation than cephalometry. In addition, the reformatting process in CT scanning is limited by the slice thickness, and error may be expected.

The total nasopharyngeal depth is established in the first or second year of life, but increase in nasopharyngeal height continues until maturity. Restriction of the nasopharyngeal airway may occur during the preschool and early school years because of adenoid hypertrophy that may exceed the typical increase in nasopharyngeal capacity [9]. Children who have otitis media with effusion have a smaller nasopharynx than other children, possibly because of a difference in the rate and timing of growth [12]. The maximum nasopharyngeal capacity may be achieved by 13.75 years in females and 17 and 18 years in males. Growth of the nasopharynx parallels the sexually determined growth of the skeleton [9]. The craniofacial skeleton develops postnatally up to age of 19 years, and all dimensions of the temporal bone and dimensions related to the ventral surface of the sphenoid bone increase until this 
Table 2 Craniofacial parameters in adults determined from two-dimensional computed tomography scans

\begin{tabular}{|c|c|c|c|c|c|}
\hline Parameter type & Side & Abbreviation & Men & Women & $P \leq^{\mathrm{a}}$ \\
\hline No. of patients & & & 30 & 30 & \\
\hline Aged (years) & & & $37 \pm 12$ & $39 \pm 12$ & NS \\
\hline \multicolumn{6}{|l|}{ Bilateral craniofacial antimeric } \\
\hline Osseous auditory tube length (mm) & Right & OATR & $13 \pm 1$ & $12 \pm 1$ & .003 \\
\hline Osseous auditory tube length & Left & OATL & $13 \pm 1$ & $12 \pm 1$ & .01 \\
\hline Cartilaginous auditory tube length (mm) & Right & CATR & $30 \pm 2$ & $29 \pm 2$ & .05 \\
\hline Cartilaginous auditory tube length & Left & CATL & $30 \pm 2$ & $29 \pm 2$ & .01 \\
\hline Mastoid depth (Henle suprameatal spine to sigmoid sinus distance) (mm) & Right & hs-ssR & $15 \pm 3$ & $15 \pm 3$ & NS \\
\hline Mastoid depth (Henle suprameatal spine to sigmoid sinus distance) & Left & hs-ssL & $15 \pm 3$ & $15 \pm 3$ & NS \\
\hline Mastoid length (mm) & Right & $\mathrm{mlR}$ & $42 \pm 4$ & $39 \pm 3$ & .001 \\
\hline Mastoid length & Left & $\mathrm{mlL}$ & $42 \pm 5$ & $38 \pm 3$ & .001 \\
\hline Jugular bulb height $(\mathrm{mm})$ & Right & ss-jbR & $13 \pm 3$ & $12 \pm 4$ & NS \\
\hline Jugular bulb height & Left & ss-jbL & $12 \pm 5$ & $11 \pm 4$ & NS \\
\hline Angle of the auditory tube & Right & AATR & $44 \pm 5$ & $45 \pm 4$ & NS \\
\hline Angle of the auditory tube & Left & AATL & $46 \pm 4$ & $47 \pm 4$ & NS \\
\hline \multicolumn{6}{|l|}{ Other } \\
\hline Intercochlear distance (mm) & & IcD & $78 \pm 4$ & $74 \pm 4$ & .001 \\
\hline Midpoints of the pharyngeal opening distance $(\mathrm{mm})$ & & mppod & $22 \pm 3$ & $21 \pm 2$ & NS \\
\hline Sella to nasion distance $(\mathrm{mm})$ & & $\mathrm{s}-\mathrm{n}$ & $61 \pm 5$ & $59 \pm 4$ & NS \\
\hline Sella to posterior nasal spine distance (posterior upper face height) (mm) & & s-pns (PUFH) & $47 \pm 4$ & $45 \pm 3$ & .02 \\
\hline Sella to basion distance $(\mathrm{mm})$ & & s-ba & $45 \pm 3$ & $44 \pm 3$ & .04 \\
\hline Nasopharynx axial area $\left(\mathrm{mm}^{2}\right)$ & & npax & $181 \pm 55$ & $177 \pm 46$ & NS \\
\hline Nasopharynx sagittal area $\left(\mathrm{mm}^{2}\right)$ & & npsag & $498 \pm 81$ & $424 \pm 53$ & .001 \\
\hline Cranial base angle & & CBA & $125 \pm 81$ & $123 \pm 6$ & NS \\
\hline Angle at sella between s-ba and s-pns ${ }^{b}$ & & A & $50 \pm 5$ & $48 \pm 4$ & NS \\
\hline
\end{tabular}

$N=60$ patients. Data reported as mean $\pm \mathrm{SD}$

${ }^{\text {a }} N S$ not significant $(P>.05)$

b Angle at sella between sella to basion distance line and line through sella and posterior nasal spine

age $[2,11,14,18]$. Therefore, we included nongrowing adults (age $>19$ years) to avoid age-related changes in the data. The present study showed significantly greater nasopharyngeal sagittal area in male than female patients, but the nasopharyngeal axial area and midpoint of the pharyngeal opening distance were similar between adult male and female subjects (Table 2). Sella to nasion distance, midpoint of the pharyngeal opening distance, and nasopharynx sagittal area correlated with IcD (Table 3).

In patients aged 10-15 years (but not other age groups), girls have a larger mastoid air cell system than boys; this sex difference may be attributed to the hormonally induced growth of the cellular system, which is faster in girls immediately before and during puberty [24]. In addition, mastoid length (porion to mastoid process length) has significant sex difference, and growth of this dimension is strongly related to physical and neural growth and development of the human head [21]. Before puberty, the mastoid system usually matures and pneumatization increases; many atelectatic conditions are halted or reversed, and the middle ear may revert to normal [16]. Mastoid length is shorter in poorly pneumatized mastoids, but there is no correlation between lateral sinus and external auditory canal distance and the degree of pneumatization; however, this information was based on a study that was performed on unselected, fresh frozen, adult temporal bones and there was no information regarding sex [25]. In our previous study, we observed statistically significant differences in mastoid length and depth between patients who had chronic otitis media and healthy sex- and age-matched adults [1]. In the present study, mastoid length was longer in men than women, but there was no difference in mastoid depth between male and female subjects (Table 2). The IcD was correlated with mastoid depth but not mastoid length (Table 3).

The auditory tube is almost flat in children and progressively rotates inferomedially to assume its final position during puberty [19]. Otitis media is most common 
Table 3 Relation between intercochlear distance and other craniofacial parameters

\begin{tabular}{|c|c|c|c|c|}
\hline Parameter & Side & Abbreviation & $r$ & $P \leq^{\mathrm{a}}$ \\
\hline Osseous auditory tube length & Right & OATR & 0.157 & NS \\
\hline Osseous auditory tube length & Left & OATL & 0.23 & NS \\
\hline Cartilaginous auditory tube length & Right & CATR & 0.155 & NS \\
\hline Cartilaginous auditory tube length & Left & CATL & 0.1 & NS \\
\hline Mastoid depth (Henle suprameatal spine to sigmoid sinus distance) & Right & hs-ssR & 0.305 & .02 \\
\hline Mastoid depth (Henle suprameatal spine to sigmoid sinus distance) & Left & hs-ssL & 0.319 & .02 \\
\hline Mastoid length & Right & $\mathrm{mlR}$ & 0.138 & NS \\
\hline Mastoid length & Left & $\mathrm{mlL}$ & 0.209 & NS \\
\hline Jugular bulb height & Right & ss-jbR & 0.145 & NS \\
\hline Jugular bulb height & Left & ss-jbL & 0.115 & NS \\
\hline Angle of the auditory tube & Right & AATR & -0.263 & .05 \\
\hline Angle of the auditory tube & Left & AATL & -0.441 & .001 \\
\hline Midpoint of the pharyngeal opening distance & & mppod & 0.491 & .001 \\
\hline Sella to nasion distance & & s-n & 0.283 & .03 \\
\hline Sella to posterior nasal spine distance (posterior upper face height) & & s-pns (PUFH) & 0.223 & NS \\
\hline Sella to basion distance & & s-ba & 0.146 & NS \\
\hline Nasopharynx axial area & & npax & 0.243 & NS \\
\hline Nasopharynx sagittal area & & npsag & 0.318 & .02 \\
\hline Cranial base angle & & CBA & 0.092 & NS \\
\hline Angle at sella between s-ba and s-pns ${ }^{\mathrm{b}}$ & & A & 0.035 & NS \\
\hline Körner (petrosquamosal) septum & Right & KSR & 0 & NS \\
\hline Körner (petrosquamosal) septum & Left & KSL & 0.187 & NS \\
\hline
\end{tabular}

$r$ correlation coefficient

${ }^{\text {a }} N S$ not significant $(P>.05)$

b Angle at sella between sella to basion distance line and line through sella and posterior nasal spine

Table 4 Comparison of craniofacial parameters for ears with and without Körner (petrosquamosal) septum

\begin{tabular}{|c|c|c|c|c|}
\hline \multirow[t]{2}{*}{ Parameter } & \multirow[t]{2}{*}{ Abbreviation } & \multicolumn{2}{|c|}{ Körner (petrosquamosal) septum ${ }^{a}$} & \multirow[t]{2}{*}{$P \leq^{\mathrm{b}}$} \\
\hline & & Present & Absent & \\
\hline \multicolumn{5}{|l|}{ Men } \\
\hline No. of patients & & $45(75)$ & $15(25)$ & \\
\hline Mastoid depth (Henle suprameatal spine to sigmoid sinus distance) & hs-ss & $15 \pm 3$ & $15 \pm 3$ & NS \\
\hline Mastoid length & $\mathrm{ml}$ & $43 \pm 5$ & $41 \pm 4$ & NS \\
\hline Jugular bulb height & ss-jb & $13 \pm 4$ & $12 \pm 4$ & NS \\
\hline \multicolumn{5}{|l|}{ Women } \\
\hline No. of patients & & $38(63)$ & $22(37)$ & \\
\hline Mastoid depth (Henle suprameatal spine to sigmoid sinus distance) & hs-ss & $15 \pm 3$ & $14 \pm 3$ & NS \\
\hline Mastoid length & $\mathrm{ml}$ & $38 \pm 4$ & $39 \pm 3$ & NS \\
\hline Jugular bulb height & ss-jb & $11 \pm 4$ & $11 \pm 4$ & NS \\
\hline
\end{tabular}

$N=30$ men and 30 women. Data reported as number $(\%)$ or mean $\pm \mathrm{SD}$

${ }^{a}$ Körner (petrosquamosal) septum thickness: men $1.0 \pm 0.2 \mathrm{~mm}$; women $0.9 \pm 0.2 \mathrm{~mm} ; P \leq .001$

${ }^{\mathrm{b}} N S$ not significant $(P>.05)$

during childhood, when tubal dysfunction is more prevalent. The decrease in the incidence of otitis media with maturity has been correlated with the shift in the position of the auditory tube, which is more vertical in adults. The change in auditory tube position is caused by growth of the craniofacial skeleton [5]. Increased length of the auditory 
tube is associated with greater degree of pneumatization of the mastoid air cell system, suggesting an association between nasopharyngeal morphology and the development of otitis media. In addition, healthy middle ears in adults typically have long auditory tubes, long distances from the midsella to the staphylion, and longer distances between the ears [23]. The latter finding is inconsistent with reports that brachycephalic people have a higher frequency of otitis media than dolichocephalic people [20]. A recent study did not support a difference in the cephalic index among children with recurrent AOM, chronic otitis media with effusion, and control subjects in which the statistical methods included provisions to control for race, sex, and age [3]. In the present study, osseous auditory tube length, cartilaginous auditory tube length, posterior upper face height (sella to posterior nasal spine distance), sella to basion distance, and Icd differed significantly between men and women (Table 2). In addition, a significant negative correlation was observed between Icd and angle of the auditory tube (Table 3).

There is controversy about the relation between pneumatization of the mastoid and high jugular bulb $[8,15]$. In the present study, no differences were observed between men and women in height of the jugular bulb (Table 2).

Körner (petrosquamosal) septum may have clinical importance because it is associated with some ear problems [7]. In addition, smaller air cell systems may be associated with larger septa [17]. In the present study, the prevalence and mean thickness of Körner septum were greater in men than women (Table 4). In addition, no differences were observed when mastoid depth, mastoid length, and jugular bulb height were compared between ears that had or did not have Körner septum (Table 4).

In summary, the present study showed that osseous auditory tube length, cartilaginous auditory tube length, mastoid length, posterior upper face height, sella to basion distance, nasopharynx sagittal area, and IcD differed significantly between men and women (Table 2). The greatest skeletal differences between men and women were observed in the vertical craniofacial dimensions. The Icd positively correlated with mastoid depth, midpoint of the pharyngeal opening distance, sella to nasion distance, and nasopharynx sagittal area but negatively correlated with angle of the auditory tube (Table 3 ). The prevalence and thickness of the Körner septum were different between men and women (Table 4). Therefore, some craniofacial parameters, especially vertical parameters, differ with sex. These differences begin in childhood and continue in adulthood. Therefore, sex must be considered when planning a craniofacial morphologic study, and results of a craniofacial morphologic study should be evaluated with caution when there is no sex matching of the patient and control groups.

Acknowledgments All financial and material support for this research was provided by Baskent University Hospital.

Conflict of interest The authors have no conflicts of interest to disclose.

Open Access This article is distributed under the terms of the Creative Commons Attribution 4.0 International License (http:// creativecommons.org/licenses/by/4.0/), which permits unrestricted use, distribution, and reproduction in any medium, provided you give appropriate credit to the original author(s) and the source, provide a link to the Creative Commons license, and indicate if changes were made.

\section{References}

1. Avci S, Ergun T, Aydin E, Kansu L (2010) Craniofacial measures of chronic otitis media patients by $2 \mathrm{D}$ reformatted CT. Clin Anat 23:374-385. doi:10.1002/ca.20967

2. Basciftci FA, Uysal T, Buyukerkmen A (2004) Craniofacial structure of Anatolian Turkish adults with normal occlusions and well-balanced faces. Am J Orthod Dentofacial Orthop 125:366-372

3. Casselbrant LM, Swarts JD, Mandel EM, Doyle WJ (2013) The Cephalic index is not different among groups of children aged 36-48 months with chronic otitis media with effusion, recurrent acute otitis media and controls. Int J Pediatr Otorhinolaryngol 77:334-337. doi:10.1016/j.ijporl.2012.11.002

4. Di Francesco R, Paulucci B, Nery C, Bento RF (2008) Craniofacial morphology and otitis media with effusion in children. Int $\mathrm{J}$ Pediatr Otorhinolaryngol 72:1151-1158. doi:10.1016/j.ijporl. 2008.03.027

5. Di Francesco RC, Sampaio PL, Bento RF (2007) Correlation between otitis media and craniofacial morphology in adults. Ear Nose Throat J 86:738-743

6. Enlow DH (1982) Handbook of facial growth, 2nd edn. WB Saunders Company, Philadelphia

7. Göksu N, Kemaloğlu YK, Köybaşioğlu A, Ileri F, Ozbilen S, Akyildiz N (1997) Clinical importance of the Korner's septum. Am J Otol 18:304-306

8. Graham MD (1977) The jugular bulb: its anatomic and clinical considerations in contemporary otology. Laryngoscope $87: 105-125$

9. Handelman CS, Osborne G (1976) Growth of the nasopharynx and adenoid development from one to eighteen years. Angle Orthod 46:243-259

10. Kemaloğlu YK, Kobayashi T, Nakajima T (2000) Associations between the eustachian tube and craniofacial skeleton. Int $\mathrm{J}$ Pediatr Otorhinolaryngol 53:195-205

11. Kitajiri M, Sando I, Takahara T (1987) Postnatal development of the eustachian tube and its surrounding structures. Preliminary study. Ann Otol Rhinol Laryngol 96:191-198

12. Maw AR, Smith IM, Lance GN (1991) Lateral cephalometric analysis of children with otitis media with effusion: a comparison with age and sex matched controls. J Laryngol Otol 105:71-77

13. McDonnell JP, Needleman HL, Charchut S, Allred EN, Roberson DW, Kenna MA, Jones D (2001) The relationship between dental overbite and eustachian tube dysfunction. Laryngoscope 111:310-316 
14. Nakamura S, Savara BS, Thomas DR (1972) Norms of size and annual increments of the sphenoid bone from four to sixteen years. Angle Orthod 42:35-43

15. Orr JB, Todd NW (1988) Jugular bulb position and shape are unrelated to temporal bone pneumatization. Laryngoscope 98:136-138

16. Sadé J, Fuchs C (1996) Secretory otitis media in adults: I. The role of mastoid pneumatization as a risk factor. Ann Otol Rhinol Laryngol 105:643-647

17. Shuknecht HF (1974) Pathology of the ear. Harvard University Press, Cambridge

18. Simms DL, Neely JG (1989) Growth of the lateral surface of the temporal bone in children. Laryngoscope 99:795-799

19. Sirikci A, Bayazit YA, Bayram M, Kanlikama M (2001) Significance of the auditory tube angle and mastoid size in chronic ear disease. Surg Radiol Anat 23:91-95
20. Stolovitzky JP, Todd NW (1990) Head shape and abnormal appearance of tympanic membranes. Otolaryngol Head Neck Surg 102:322-325

21. Takeuchi Y, Savara BS, Shadel RJ (1980) Biennial size norms of eight measures of the temporal bone from four to twenty years of age. Angle Orthod 50:107-113

22. Todd NW Jr (1983) Otitis media and eustachian tube caliber. Acta Otolaryngol Suppl 404:1-17

23. Todd NW (1998) Cranial anatomy and otitis media: a cadaver study. Am J Otol 19:558-564

24. Tos M, Stangerup SE (1985) Secretory otitis and pneumatization of the mastoid process: sexual differences in the size of mastoid cell system. Am J Otolaryngol 6:199-205

25. Turgut S, Tos M (1992) Correlation between temporal bone pneumatization, location of lateral sinus and length of the mastoid process. J Laryngol Otol 106:485-489 